\title{
An Integrated Approach to Hydrographic Surveying of Large Reservoirs-Application to Tarbela Reservoir in Pakistan
}

\author{
Sarfraz Munir ${ }^{1}$, Muhammad Armaghan ${ }^{2}$, Arsalan Babrus ${ }^{3}$ \\ ${ }^{1}$ Water Resources Engineering Program, University of Kurdistan Hewler, Kurdistan Region, Iraq \\ ${ }^{2}$ MM Pakistan (Pvt.) Ltd., Lahore, Pakistan \\ ${ }^{3}$ Water and Power Development Authority, Tarbela Dam Project, Haripur, Pakistan \\ Email: s.munir@ukh.ac, armaghanmuhammad@gmail.com
}

Received 8 August 2014; revised 9 September 2014; accepted 8 October 2014

Copyright (C) 2014 by authors and Scientific Research Publishing Inc.

This work is licensed under the Creative Commons Attribution International License (CC BY).

http://creativecommons.org/licenses/by/4.0/

(c) (i) Open Access

\begin{abstract}
Hydrographic surveying in reservoirs is a key activity in order to collect data for a variety of purposes like estimation of storage capacity, rate and pattern of sediment deposition, movement of underwater sediment delta and reservoir routing, etc. These parameters play a pivotal role in any planning, management and operation activity of the reservoirs. Traditional approaches to perform hydrographic surveying in Indus Basin are time consuming, laborious, comparatively inaccurate and costly. As water resources are under immense pressure due to a variety of factors, such inefficient methods are not acceptable for efficient water management. In this study, an integrated approach for hydrographic surveying is introduced and evaluated in terms of its efficiency in comparison with the traditional methods of hydrographic surveying. The approach develops an integrated environment of hydrographic surveying comprising human, hardware and software. The process of surveying starts from in-house planning using specialized geo-spatial softwares. Then, on site a combination of computer hardware, echosounder, differential global positioning system (DGPS), survey vessel and survey crew is made. Post-processing is performed after conducting a survey in order to improve quality of data by filtering errors and producing the end product like reservoir underwater terrain, development of reservoir stage-area and stage-storage relationships, etc. The study was applied to Tarbela Reservoir, Pakistan.
\end{abstract}

\section{Keywords}

Hydrographic Survey, Bathymetric Survey, Tarbela Reservoir, Reservoir Capacity, Differential GPS, Echosounder 


\section{Introduction}

Data collected through hydrographic surveying play a pivotal role in decision making for short term and long term planning, operation and management of the reservoir [1]. Generally, in water resources engineering and management projects in Indus Basin the traditional methods of hydrographic surveying are adopted, although these methods served the purpose to a large extent in the past. But now, water resources are under immense pressure due to various factors and need a variety of information in order to take timely and informed decisions for efficient management of water. The traditional methods do not have the capacity to deal with such data in an efficient way.

In case of Tarbela Reservoir, the traditional method of hydrographic surveying consists of a large set of heavy and complicated equipment. The equipment consists of mainly echosounders, printers, time tagging machine, wireless communication sets, mini rangers, power batteries and theodolites, etc. [2]. Accordingly, a large crew is required onboard in order to mount and operate the equipment.

This is not the case only with Tarbela Reservoir, but almost in every major water project in Indus Basin the same approach is adopted. The situation with Provincial Irrigation Departments (PIDs) in Indus Basin, which are the backbone of agricultural production in the country, is even worse. The PIDs have been practicing century old hydrographic surveying techniques. These techniques mainly consist of sounding rod, sounding probe with very crude distance/depth measuring techniques. These techniques are outdated now and in no way are capable of meeting the demands of an accurate hydrographic surveying.

Difficulties and limitations in hydrographic data collection with traditional and some outdated practices make the need of introducing some efficient techniques for these surveys. In this paper an effort is made to introduce and evaluate an integrated approach of hydrographic surveying. This approach will address most of the above mentioned deficiencies up to a large extent. Furthermore, the new approach is compared with the traditional methods in several ways in order to understand the efficiency of the new approach. The main parameters of comparison are the time, accuracy and ease of operation. At the end of the paper, variety and sophistication in the output from this approach is discussed.

\section{Methods and Approach}

\subsection{Hydrology of Tarbela Dam}

Tarbela Dam was constructed in 1974 in Indus River at Tarbela, Haripur District, Pakistan. It is located about $100 \mathrm{~km}$ away from Islamabad in the North-west direction. The dam is located at $34^{\circ} 5^{\prime} 16.61^{\prime \prime} \mathrm{N}, 72^{\circ} 41^{\prime} 55.566^{\prime \prime} \mathrm{E}$. The main dam is an earth core rock fill type with a length of 2743 meters and 148 meters high [3]. The reservoir is about $100 \mathrm{~km}$ long, but analysis is confined up to $15 \mathrm{~km}$ upstream of the dam. Figure 1 shows layout of the Tarbela Reservoir.

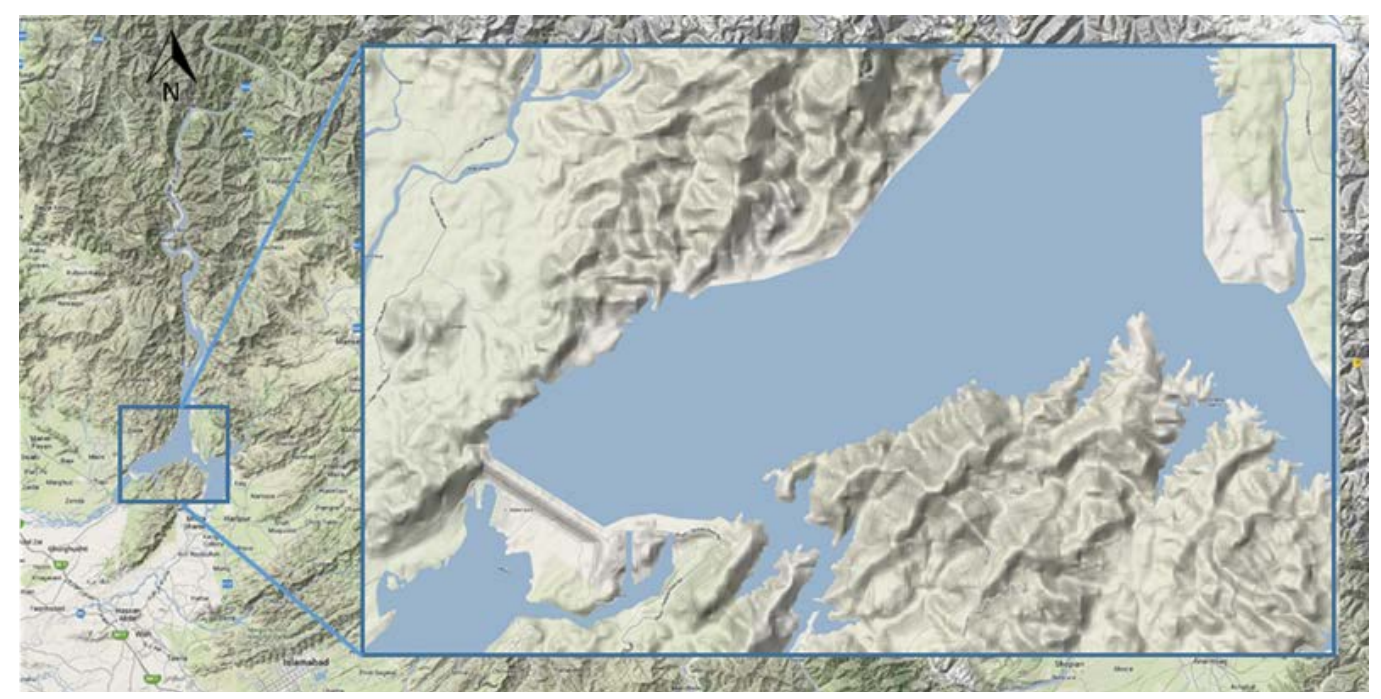

Figure 1. Layout of Tarbela Reservoir with study area. 
Length of Indus River upstream of Tarbela Dam is about $1100 \mathrm{~km}$ with a basin area of about $169,645 \mathrm{~km}^{2}$. Most of the upper Indus Basin area consists of snow covered high mountains, whereas monsoon area of the basin covers only 10,360 $\mathrm{km}^{2}$ just above Tarbela [4]. Indus River carries enormous amounts of sediments, which deposits in the reservoir and is the main reason of decrease in storage volume. Sedimentation reduces the capacity of reservoir over time, which is monitored through hydrographic surveying and the annual buildup of sediments is computed. Figure 1 presents an overview of Trabela Reservoir.

\subsection{New Integrated Approach}

The new integrated approach of hydrographic surveying, under discussion, consists of meaningful combination of hardware, software and human. It mainly consists of Differential Global Positioning System (DGPS), echosounder with transducer, field computer [5] and reliable power supply. Two softwares are mainly used; one is for collecting bathymetric data, the bathy 2010 Software, and the other is Hypack. Hypack Software, in this approach played central role and involved in all stages of surveying from in-house survey planning to produce the sophisticated end products.

Reservoir sounding data including sub-bottom profiling was collected using $3.5 \mathrm{kHz}$ Chirp sub-bottom profiler. The transducer was connected with Bathy 2010 Echosounder. The 3D positioning data were collected through differential GPS. Differential corrections were received in real time through geostationary satellite (OmniStar). SyQwest Echsounder was operated through Bathy 2010 Software. All position and sounding data were stored in Bathy 2010 Software. From Bathy 2010 Software, data were exported to Hypack. Hypack then stored all the data and guided in maintaining the survey vessel position. Figure 2 shows a field setup of integrated hydrographic surveying approach.

\subsection{Pre-Survey Planning}

In order to conduct an accurate and efficient survey, there are some pre-survey planning steps [6], which need to be taken before the actual survey as shown in Figure 3. The pre-survey planning mainly includes acquisition of the background image of the study area, which may be obtained from Google Earth, through remote sensing or aerial photography, and then importing the image to Hypack Software for geo-referencing. After geo-referencing, the image is used for drawing the survey paths as shown in Figure 4.

\subsection{Performing Hydrographic Survey}

In hydrographic surveying with this approach, generally a crew of three members is involved, one is the boatman to operate and maintain the survey vessel's position on planned survey paths. Second member is to operate

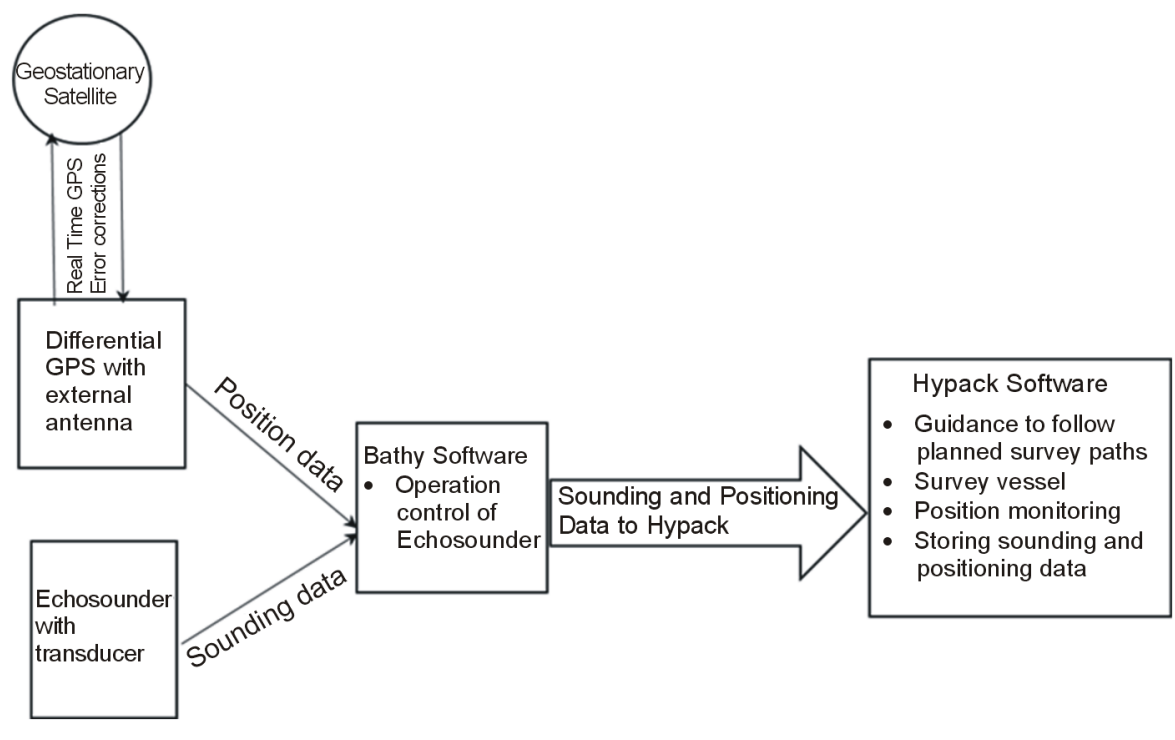

Figure 2. Field setup of integrated hydrographic surveying approach. 


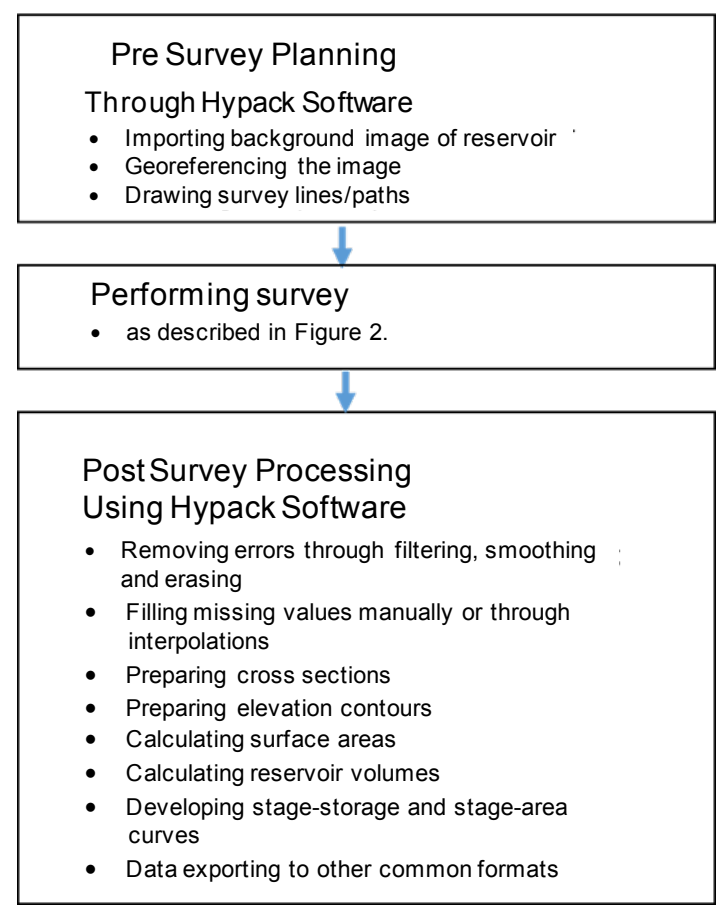

Figure 3. Step by step hydrographic surveying procedure.

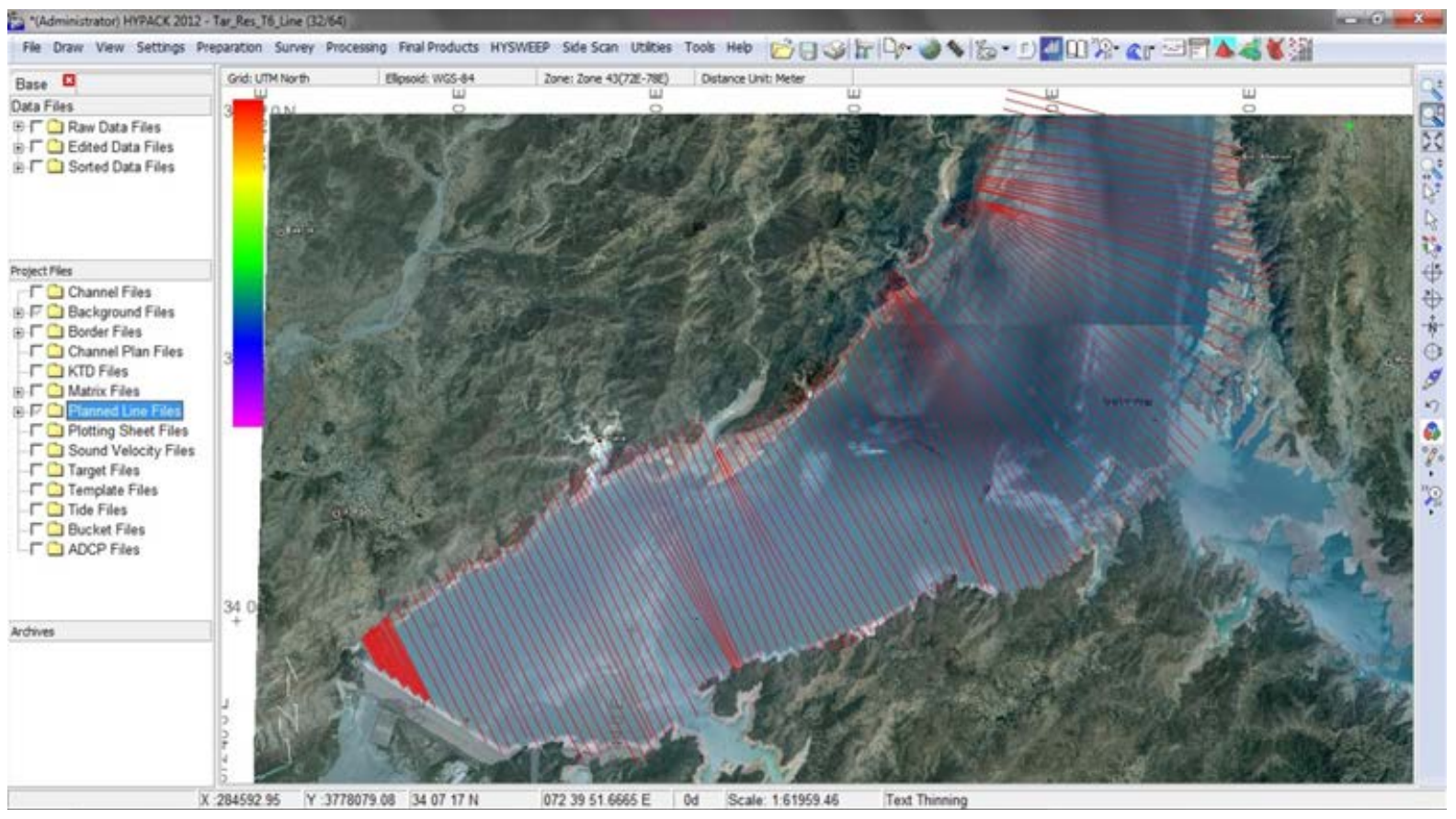

Figure 4. Planned survey paths prepared in Hypack 2012 Software.

the equipment and the third member may be required for equipment mounting and/or as boat helper. The transducer is mounted on one side of the boat, with DGPS antenna directly above it. Survey is performed on the planned survey paths, as decided in the in-house planning. The echosounder and DGPS start data acquisition simultaneously, using Bathy 2010 Software and Hypack 2012 Software, in this case. The survey vessel is maneuvered on the pre-defined survey paths. Data collection interface with Bathy 2010 Software is shown in Figure 5. 


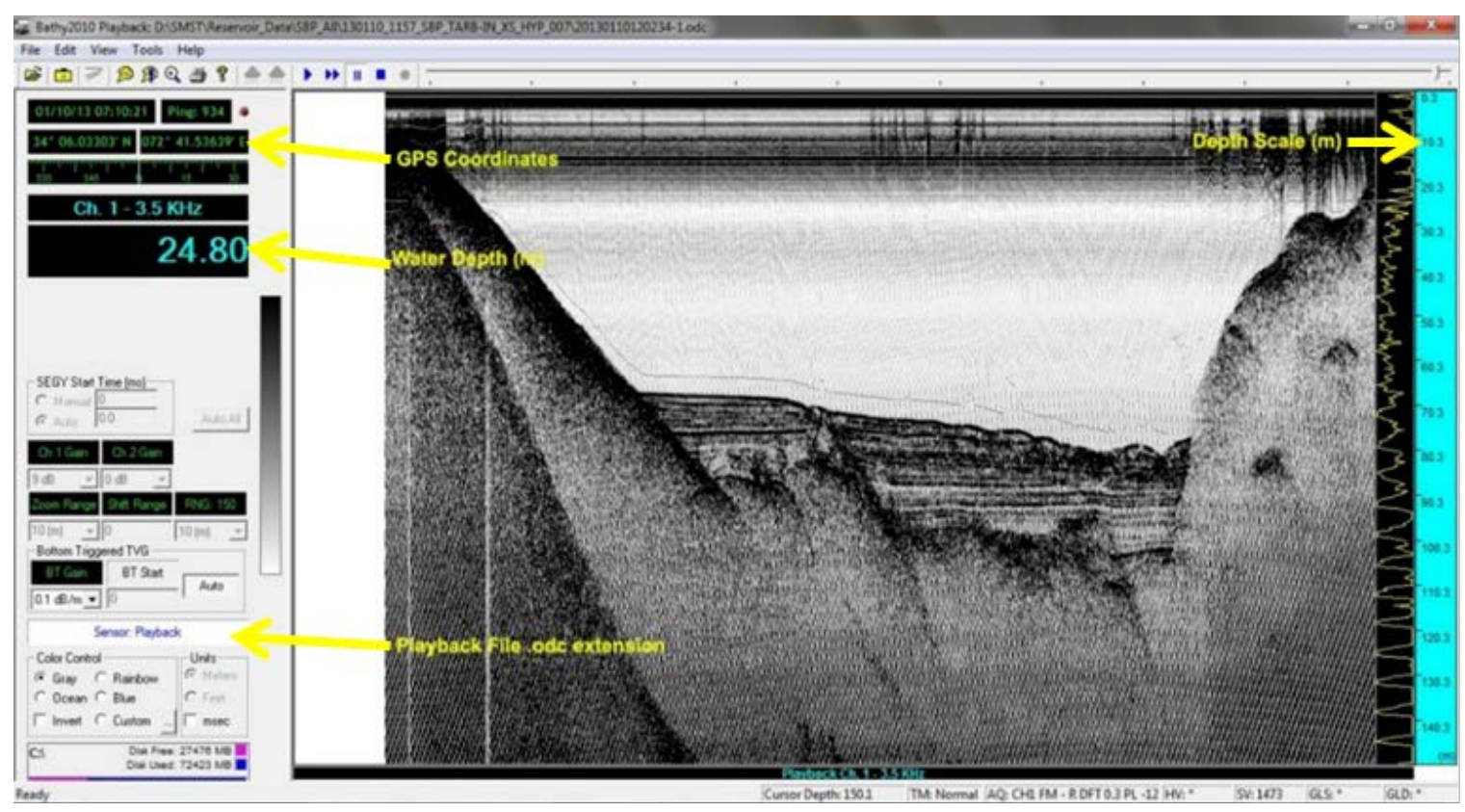

Figure 5. Bathymetric and sub-bottom profiling data collection with Bathy 2010 Software.

\subsection{Post Processing}

Post processing is the most important part of hydrographic surveying. It is mainly performed in order to improve the quality of collected data by removing errors and filling gaps for missing data. After improving the quality, the data are used to produce the end products. Raw bathymetric data are processed and analyzed in Hypack Software in order to filter multiple return acoustic signals, soundings with random errors and noise, GPS error and remaining gap near shore for inaccessible areas with the boat. The Raw data are viewed, corrected and saved in edit files as shown in Figure 6.

In order to determine the reservoir area and reservoir volume from survey data, a variety of options is available in the Hypack Software including Triangular Irregular Network (TIN). A TIN is a vector data structure that partitions geographic space into contiguous, non-overlapping triangles. The vertices of each triangle are sample data points with $\mathrm{X}, \mathrm{Y}$, and $\mathrm{Z}$ values [7]. These sample points are connected by lines to form Delaunay triangles. TINs are used to store and display surface models (ESRI). A digitized polygon enclosing the collected data can be developed such that interpolation is not allowed to come outside the boundary.

\section{Results and Discussion}

A variety of options is available in the Hypack Software to present the survey results and to produce the final products.

After the collection of bathymetric data of Tarbela cross section, the $\mathrm{X}, \mathrm{Y}$, and $\mathrm{Z}$ data were imported in Hypack 2012. The cross-section data were combined into a single point dataset. Contour lines and TIN model of the bottom surface were generated [8] from the resulting profiles for the generation of a final bathymetric map.

A stage-storage relationship was developed by calculating storage volumes on different elevations of reservoir, and presented in Figure 7. There are several methods available for determining the reservoir volume but the most accurate is TIN surface model [9] [10]. TIN is most suitable model due to dense spatial data and irregular shape of the reservoir. The calculated storage volume in Tarbela reservoir is $3.83 \mathrm{BCM}$ (3.1 MAF) in 15 $\mathrm{km}$ reservoir area from the main dam.

In Figure 8, the pivot point, foreset slope, bottomset slope and the topset slope are very much evident. The pivot point on left side of the reservoir is close to the dam as compared to right side. In 2012 the pivot point was located about $8.4 \mathrm{~km}$ to $9.6 \mathrm{~km}$ from the intakes and from 7.5 to $9.1 \mathrm{~km}$ from the center line of the main dam. During 2012 bathymetric survey, the deepest bed surface was observed to be $104 \mathrm{~m}$, near the intake of the dam. The depth of the Tarbela reservoir reduces gradually towards the upstream of reservoir and tributaries. 


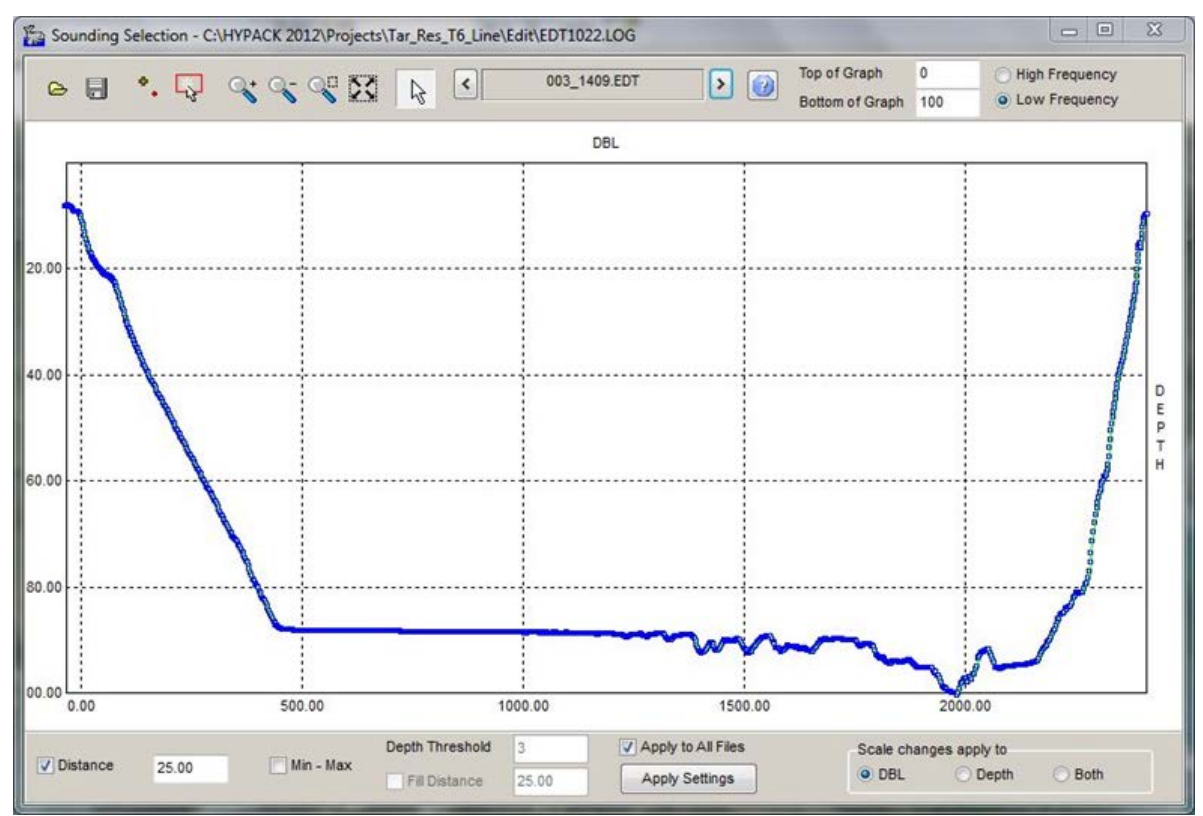

Figure 6. Edited bathymetry data collected from planned line at $700 \mathrm{~m}$ from dam.

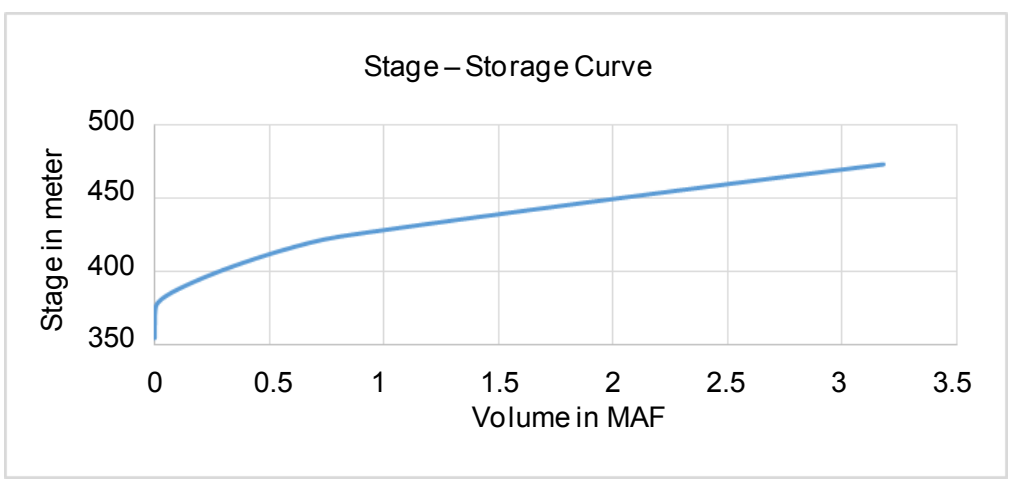

Figure 7. Stage-storage curve for Tarbela Reservoir in 2012 up to $15 \mathrm{~km}$ from the main dam.

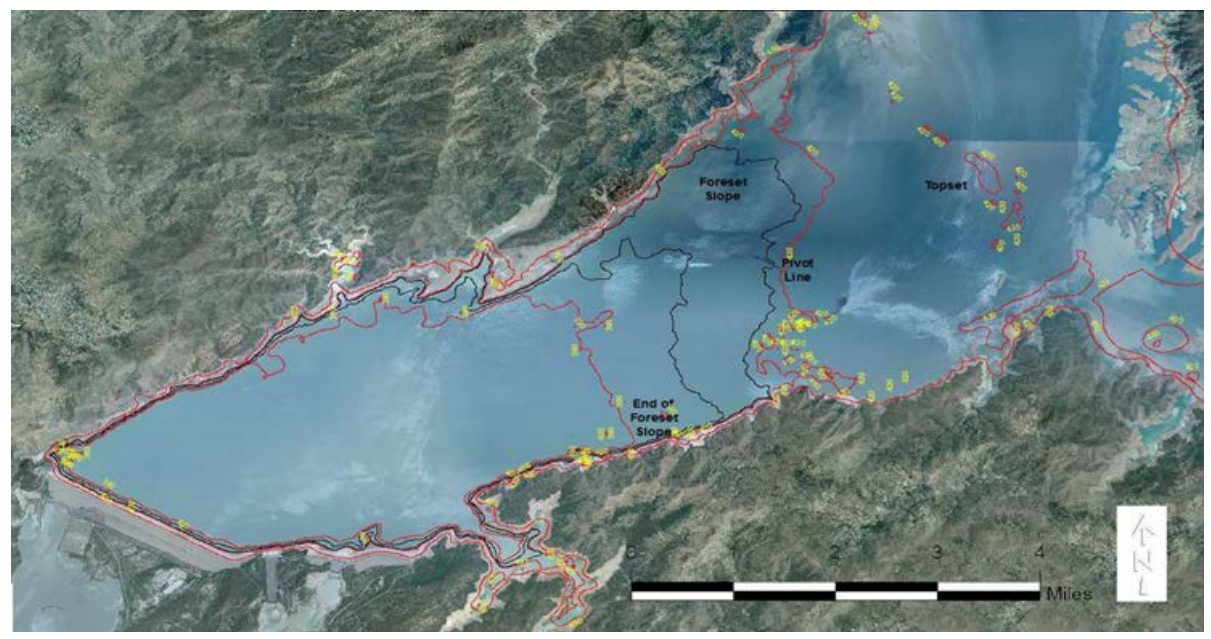

Figure 8. Map of Tarbela Reservoir showing detailed slope of bottom surface profiling using Hypack 2012. 


\section{Comparison with Traditional Approach}

Table 1 presents a comparison of traditional survey method and the modern approach of hydrographic surveying. It is evident from facts that the modern approach is much efficient and accurate for conducting hydrographic surveys. The end products like computation of stage-storage relationship (Figure 7), development of 3D reservoir surface (Figure 9) and creation of contour map (Figure 10), etc. make it evident that the modern approach produces much better products from the survey, as compared with the traditional method.

\section{Conclusion}

In this paper an integrated approach of hydrographic surveying was introduced, elaborated and compared with the traditional approaches. It has been found that the new integrated approach is more efficient in terms of saving resources (humans and time), improving accuracy, ease of operation of the equipment, automatic analytical facilities and a large variety of end products. End products for a reservoir mainly include accurate stage-areas and stage-storage relationships, generation of 3D reservoir surface, creation of contour map of the reservoir elevations, etc. In comparison with conventional approaches the integrated approach reduces the survey crew to about three persons instead of 15 in conventional approaches. Survey can be performed in much less time as compared to

\section{Table 1. Comparison of traditional survey and modern approach of hydrographic surveying.}

\begin{tabular}{|c|c|c|c|}
\hline Sr. No. & Item & Traditional Method & Integrated Approach \\
\hline 1 & Main equipment & $\begin{array}{l}\text { Multi-frequency single beam echosounder, digital } \\
\text { printer data (tabular), time tagging machine, mini } \\
\text { rangers, theodolites, power batteries, wireless } \\
\text { radio, control station (Burgee) }\end{array}$ & $\begin{array}{l}\text { Multi-frequency single beam echosounder } \\
\text { Differential GPS, Power source }\end{array}$ \\
\hline 2 & Software & & Hypack ${ }^{\circledR}$, Bathy 2010 \\
\hline 3 & Survey crew & About 15 persons & 3 persons \\
\hline 4 & Time & Six weeks required covering whole reservoir & One week \\
\hline 5 & $\begin{array}{l}\text { Post processing/ } \\
\text { Calculations }\end{array}$ & Eight weeks & One week \\
\hline 6 & $\begin{array}{l}\text { Preparation of maps } \\
\text { and other products }\end{array}$ & Twelve weeks after completion of survey & One week after completion of survey \\
\hline 7 & Product's type & $\begin{array}{l}\text { Contour map of reservoir surface, stage-storage } \\
\text { relationship, reservoir capacity }\end{array}$ & $\begin{array}{l}\text { Reservoir's under water terrain, storage } \\
\text { capacity, stage storage relationship, three } \\
\text { dimensional reservoir surface }\end{array}$ \\
\hline
\end{tabular}

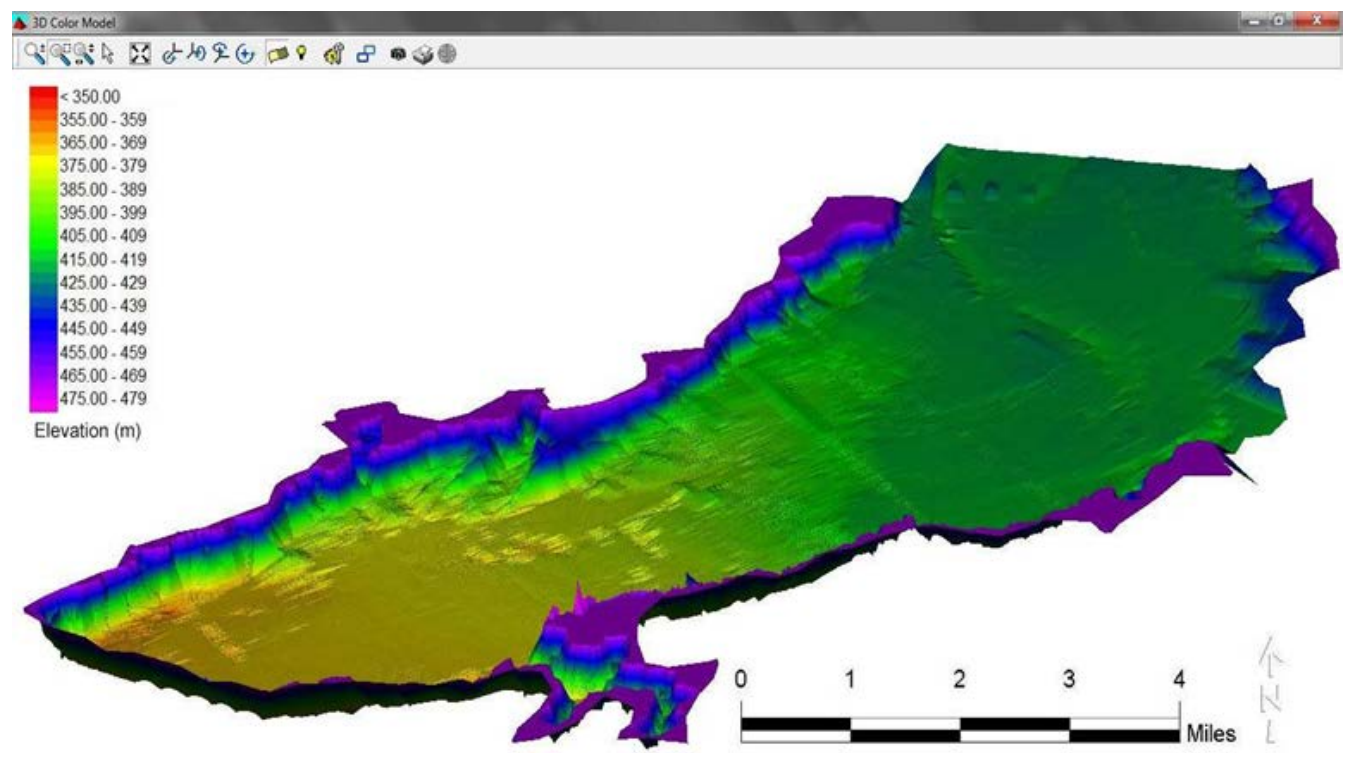

Figure 9. Generated 3D surface of the reservoir in 2012 up to $15 \mathrm{~km}$ from the main dam. 


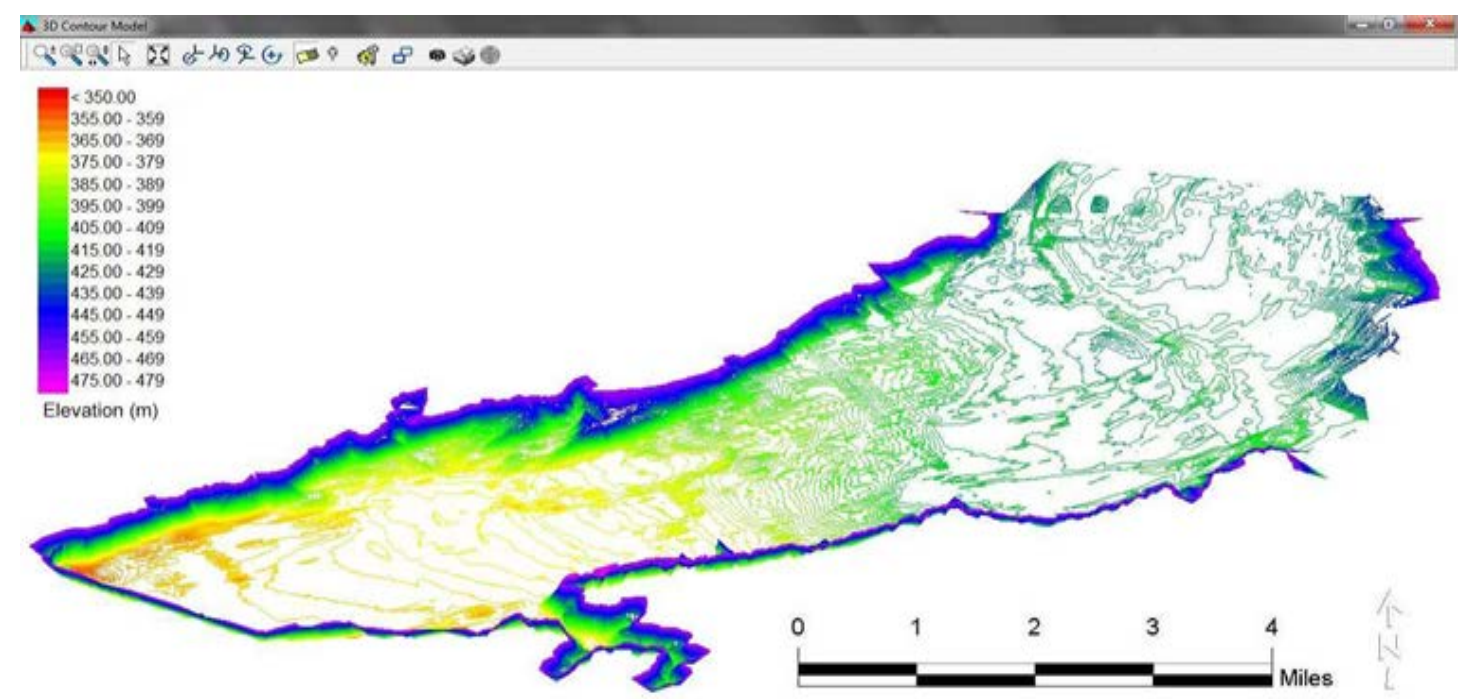

Figure 10. Reservoir surface elevation contour map with $20 \mathrm{~m}$ interval.

traditional approaches, as in case of Tarbela Reservoir it can be performed in one week, instead of four weeks in old approach. Similarly, data analysis and interpretation can be performed in one week with a large variety of end products, instead of two to three months in traditional approaches, with limited variety of end products.

\section{Acknowledgements}

Authors acknowledge the cooperation of WAPDA on facilitating with survey and providing the previous data. Authors also are grateful for the help of colleagues Mr. Muhammad Ahmad Khan, Mr. Waqas Sikandar and Mr. Zahoor Ahmed helping in conducting this research.

\section{References}

[1] Melvin, J.U. and Rockville, M.D. (1976) Hydrographic Manual Forth Edition. USA Department of Commerce, National Oceanic and Atmospheric Administration (NOAA), Nation Ocean Service (NOS), Washington DC, 1-13.

[2] Barry, W.M. and Dale, H. (1989) Technical Report HL-89-21 Small Boat Survey System. Survey and Mapping Research and Development Program, Department of the Army, Waterways Experiment Station, Corps of Engineer, Vicksburg, $9-15$.

[3] Marta, R. (2012) Tarbela Dam in Pakistan. Case Study of Reservoir Sedimentation. River Flow 2012: Proceedings of the International Conference on Fluvial Hydraulics, San José, 5-7 September 2012, 1-9. http://eprints.hrwallingford.co.uk/567/

[4] Pakistan Space and Upper Atmosphere Research Commission (2013) Estimation of Snow Cover for Year 2013 (Indus Basin).

[5] Ronald, L.F. (2009) Clear Lake 2007 Hydrographic Survey. Technical Report No. SRH-2009-36, USA Department of Interior Bureau of Reclamation Technical Service Center Water and Environmental Resources Division Sedimentation and River Hydraulics Group Denver, Colorado, 4-11.

[6] Ronald, F. and Kent, C. (2008) Erosion and Sedimentation Manual-Reclamation and Managing Water in the West, USA Department of the Interior Bureau of Reclamation, Washington DC, 7- 41.

[7] Kennedy, H. (2001) Dictionary of GIS Terminology Redlands. Environmental System Research Institute, Inc., Redlands, 116.

[8] Sorin, D.G., Romania, C.C. and Nicolae, J. (2007) Trend of Standards for Hydrographic Survey. Proceedings of the 5th IASME/WSEAS International Conference on Heat Transfer, Thermal Engineering and Environment, Athens, 25-27 August 2007, 256-262.

[9] Oklahoma Water Resources Board (2005) Hydrographic Survey of Dave Boyer (Walters) Lake. Oklahoma Water Resources Board, Oklahoma City, 4-22.

[10] The Water Agency (2009) Final report: Hydrographic Survey of W.R. Holway Reservoir. Oklahoma Water Resources Board, Oklahoma City, 5-27. 
Scientific Research Publishing (SCIRP) is one of the largest Open Access journal publishers. It is currently publishing more than 200 open access, online, peer-reviewed journals covering a wide range of academic disciplines. SCIRP serves the worldwide academic communities and contributes to the progress and application of science with its publication.

Other selected journals from SCIRP are listed as below. Submit your manuscript to us via either submit@scirp.org or Online Submission Portal.
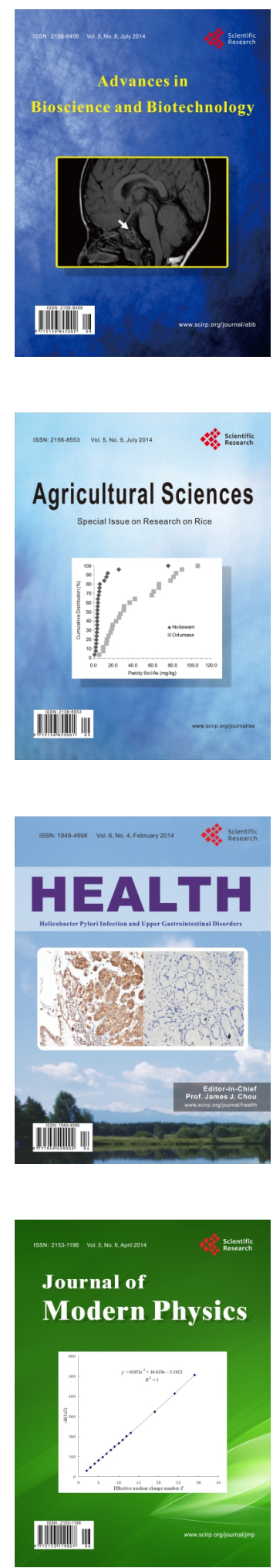
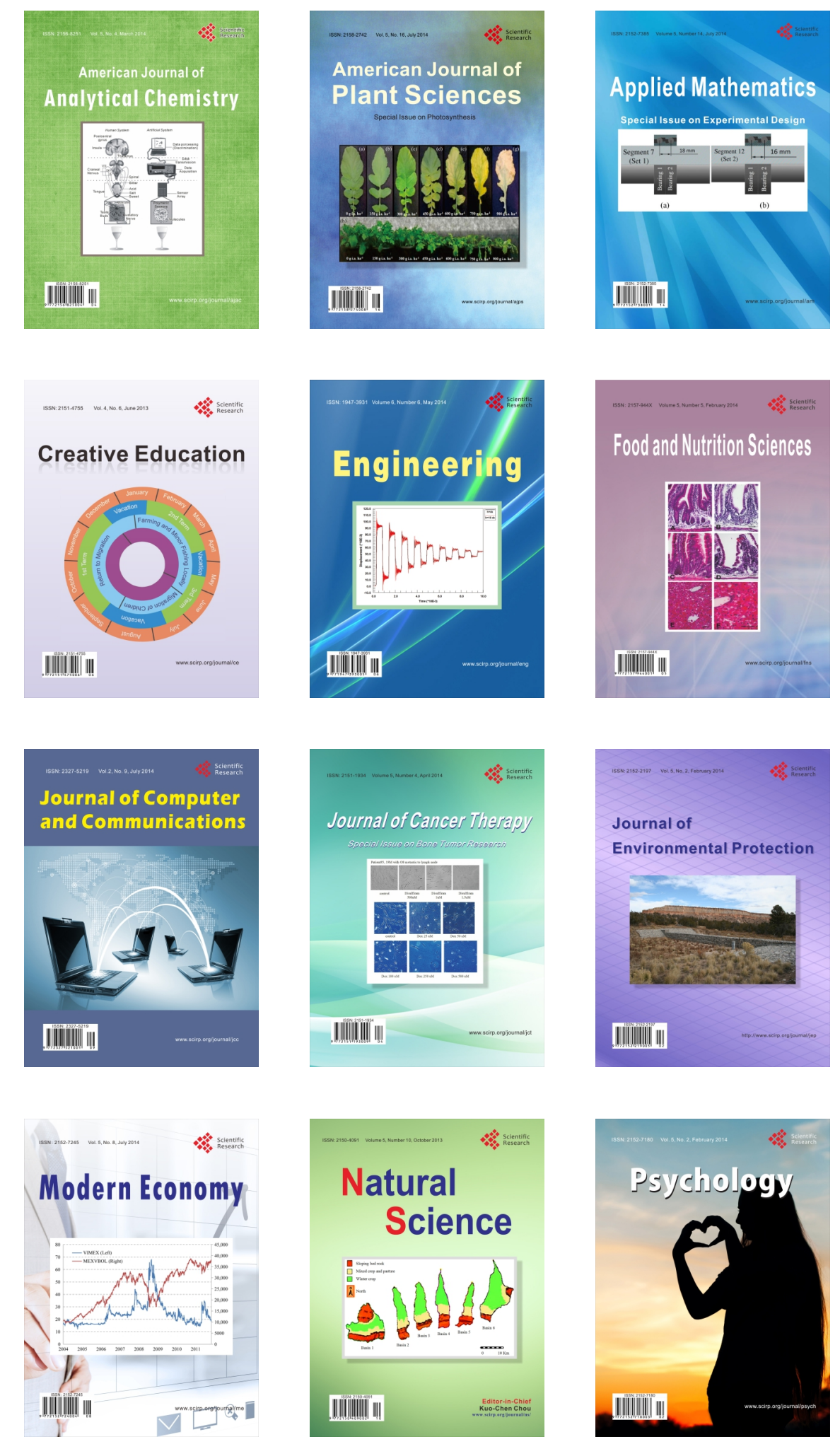